\title{
Retraction Note to: siRNA-participated chemotherapy: an efficient and specific therapeutic against gastric cancer
}

\author{
Donglei Zhou ${ }^{1} \cdot$ Xun Jiang $^{1} \cdot$ Weixing Ding ${ }^{1} \cdot$ Lijun Zheng $^{1} \cdot$ Lei Yang $^{1} \cdot$ \\ Chengzhu Zheng ${ }^{2} \cdot$ Liesheng $\mathrm{Lu}^{1}$
}

Published online: 17 August 2015

(C) Springer-Verlag Berlin Heidelberg 2015

\section{Retraction Note to: J Cancer Res Clin Oncol (2013)}

\section{9:2057-2070}

DOI 10.1007/s00432-013-1492-3

The Publisher and Editor retract this article in accordance with the recommendations of the Committee on Publication Ethics (COPE). After a thorough investigation we have strong reason to believe that the peer review process was compromised.

The online version of the original article can be found under doi: 10.1007/s00432-013-1492-3.

Liesheng Lu

luleishenga@hotmail.com

1 General Surgery Department, The Tenth People's Hospital Affiliated to Tongji University, No. 301 Yanchang Middle Road, Zhabei District, Shanghai 200072, China

2 General Surgery Department, Changhai Hospital Affiliated to the Second Military Medical University, Shanghai 200433, China 